\title{
Exposição de fibroblastos provenientes de pterígios recidivados e da cápsula de Tenon normal ao tacrolimus (FK-506)
}

\author{
Fibroblasts from recurrent pterygium and normal Tenon's capsule \\ exposed to tacrolimus(FK-506)
}

\author{
Clodomir S. C. de Carvalho ${ }^{1}$ \\ Magda Massae Hata Viveiros ${ }^{2}$ \\ Silvana Artioli Schellini ${ }^{3}$ \\ João Manoel Grisi Candeias ${ }^{4}$ \\ Carlos RobertoPadovani ${ }^{5}$
}

\section{RESUMO}

Objetivo: Avaliar a taxa de proliferação de fibroblastos provenientes de pterígios recidivados e da cápsula de Tenon normal, quando expostos in vitro ao tacrolimus (FK 506). Métodos: Foi realizado estudo prospectivo, controlado, avaliando-se 8 amostras de explantes de cápsula de Tenon de pterígios recidivados e 6 de cápsula de Tenon normal, obtidas na Faculdade de Medicina de Botucatu - UNESP. A cápsula de Tenon normal foi colhida da região temporal inferior, do mesmo portador de pterígio. As amostras foram cultivadas em meio específico e posteriormente expostas ao tacrolimus 1M (FK 506), em única exposição, com avaliação da taxa de proliferação celular 1,5, 12 e 19 dias após a exposição. Resultados: Avaliando-se a proliferação dos fibroblastos provenientes de cápsula de Tenon de pterígios recidivados e da cápsula de Tenon normal, os fibroblastos expostos ao tacrolimus tiveram taxa de proliferação significativamente menor $(\mathrm{p}<0,05)$ do que quando não houve exposição a droga, quando a avaliação foi feita 1 dia após a exposição. Quando a avaliação foi feita 19 dias após a exposição, a taxa de proliferação foi maior nos grupos expostos a droga. Conclusão: Os fibroblastos provenientes da cápsula de Tenon de pterígios recidivados apresentaram taxa de proliferação significativamente menor um dia após a exposição ao tacrolimus. Novos estudos devem ser realizados para definir dose e tempo de exposição dos fibroblastos a droga, com o intuito de definir se o tacrolimus pode ser útil como tratamento coadjuvante do pterígio.

Descritores: Pterígio/patologia; Fibroblastos/patologia; Técnicas de cultura de células; Proliferação de células; Recidiva; Tracolimus/uso terapêutico

\section{INTRODUÇÃO}

Na gênese do pterígio, a inflamação crônica pode ser um fator que gera crescimento da conjuntiva sobre a córnea, supondo-se que os linfócitos $\mathrm{T}$ possam estar envolvidos ${ }^{(1)}$.

O tacrolimus é um antibiótico macrolídeo, extraído da fermentação de um caldo do microrganismo Streptomyces tsukubaensis. Em animais, demonstrou-se que o tacrolimus (FK-506) causa supressão da imunidade humoral e inibe a ativação do linfócito $\mathrm{T}$, apesar de seu exato mecanismo de ação não ser conhecido. Evidências experimentais sugerem que o tacrolimus se liga a uma proteína intracelular (proteína de ligação do FK-506), formando um complexo que se liga a calcineurina e inibe a atividade da serina-treonina, inibindo assim a expressão de linfocinas, a apoptose e a degranulação ${ }^{(2)}$. 
Apesar do FK-506 apresentar propriedades imunossupressoras muito similares a ciclosporina, com uma potência 100 vezes maior que aquela ${ }^{(2)}$, são escassos na literatura os ensaios utilizando o FK-506 em cultura de células fibroblásticas.

Desta forma, foi desenvolvido este estudo que teve por objetivo avaliar o efeito do FK-506 sobre fibroblastos provenientes de pterígios recidivados e da cápsula de Tenon normal.

\section{MÉTODOS}

Este é um estudo prospectivo, controlado, aprovado pela Comissão de Ética em Pesquisa em Seres Humanos e executado na Faculdade de Medicina de Botucatu - UNESP, tendo a participação de 14 portadores de pterígio recidivado.

Todos os indivíduos foram operados, tendo sido removidos o pterígio e fragmentos da cápsula de Tenon da região do corpo do pterígio e fragmentos da cápsula de Tenon normal, localizada no fórnice temporal inferior, do mesmo olho acometido. O primeiro espécime a ser removido foi o tecido são.

Adotou-se como critério de exclusão, os indivíduos portadores de pterígio temporal ou nasal e temporal, no mesmo olho.

Imediatamente após a remoção, os fragmentos de cápsula de Tenon foram acondicionados em tubos Ependorff estéreis e hermeticamente fechados, sendo estocados à temperatura de $5^{\circ} \mathrm{C}$ para transporte em período inferior a três horas após a exérese, para o laboratório de Imunologia do Departamento de Microbiologia e Imunologia - Instituto de Biociências, Universidade Estadual Paulista - UNESP.

Sob condições de assepsia e em câmara de fluxo laminar, as amostras foram colocadas em placas de Petri de $35 \mathrm{~mm}$ e lavadas com meio DMEM/F12 (Gibco -USA, suplementado com: $5 \mathrm{ml} / \mathrm{l}$ de vitaminas TC minimal Eagle 100X, 0,01 U/ml de insulina, 1,4 g/l de bicarbonato de sódio, $400.000 \mathrm{U} / \mathrm{ml} \mathrm{de}$ penicilina, $40 \mathrm{mg} / \mathrm{ml}$ de gentamicina, $5 \mathrm{mg} / \mathrm{ml}$ de anfotericina-B, $15 \mu \mathrm{g} / \mathrm{l}$ de glutationa, com $\mathrm{pH}$ final de 7,0), para a remoção do excesso de células sanguíneas e, então, cortadas em fragmentos de aproximadamente $1 \mathrm{~mm}^{2}$ com pinça e tesoura cirúrgicas delicadas e estéreis. Estes fragmentos foram colocados em frascos poliestireno estéreis para cultura de células, de $25 \mathrm{~mm}^{2}$ (TPP), com $1 \mathrm{ml}$ de meio DMEM/F12, suplementado com 15\% de soro fetal bovino (SFB) e mantidos em estufa a $37^{\circ} \mathrm{C}$ com $5 \%$ de $\mathrm{CO}_{2}$.

A adição de meio DMEM/F12 com SFB a $15 \%$ foi feita a cada 3 dias, com acompanhamento e exames das culturas sob microscópio de inversão, para a observação da morfologia e comportamento dos fibroblastos (aderência, migração e proliferação) até que se obtivesse um número satisfatório de células em cultura (Figura 1), definido pela observação de células com alta atividade mitótica e não confluentes, ocupando aproximadamente $2 / 3$ da capacidade do frasco, quando então, prosseguiu-se com a repicagem das células.

Para o subcultivo (ou repicagem) das células, retirou-se o meio DMEM/F12 com SFB utilizando pipeta de Pasteur e realizou-se o enxágüe cuidadoso dos frascos com solução PBS
(Phosphate buffered saline), a seguir os mesmos foram incubados com uma solução de EDTA (Gibco - USA) e tripsina Vercese $0,2 \%$ (Instituto Adolfo Lutz), durante três minutos, em estufa a $37^{\circ} \mathrm{C}$.

Com o microscópio de inversão, observou-se o desprendimento das células e então inativou-se a tripsina com a adição de $2 \mathrm{ml}$ de meio DMEM/F12, acrescido com $20 \%$ de SFB. Esta suspensão celular foi, então, dividida em duas partes iguais, ficando uma no mesmo frasco e outra em um novo frasco estéril. Ambos foram colocados novamente em estufa até chegarem a semiconfluência, quando então foram novamente subcultivadas até se chegar ao terceiro subcultivo.

\section{Método para exposição das culturas ao tacrolimus}

Foram selecionadas para exposição ao tacrolimus as amostras que alcançaram contagem suficiente para a distribuição igualitária em 16 do total de 24 poços dos Multiwells.

Foram distribuídos 5.000 fibroblastos em cada poço, sendo que o método para retirada dessas células em subcultivo foi semelhante aos subcultivos anteriores.

Através da contagem das células, distribuiu-se cada amostra em 16 quantidades iguais de fibroblastos, para que, em cada momento de contagem, fossem utilizados 4 poços dos Multiwells.

Vinte e quatro horas após a distribuição das células nos Multiwells, foi feita a exposição dos fibroblastos ao tacrolimus $1 \mathrm{M}$ em 3 de cada 4 poços que continham os fibroblastos, num total de 12 compartimentos contendo tacrolimus $1 \mathrm{M}$ e 4 sem ter sido expostos (utilizados como controles de não exposição a droga). Todos os 16 poços de cada amostra foram completados com 0,5 ml do meio de cultura (DMEM/F12 acrescido com $20 \%$ de SFB).

Portanto, a pesquisa em cada um dos indivíduos foi realizada em triplicata para que a contagem dos fibroblastos fosse mais confiável, tendo sido a exposição ao tacrolimus feita uma única vez.

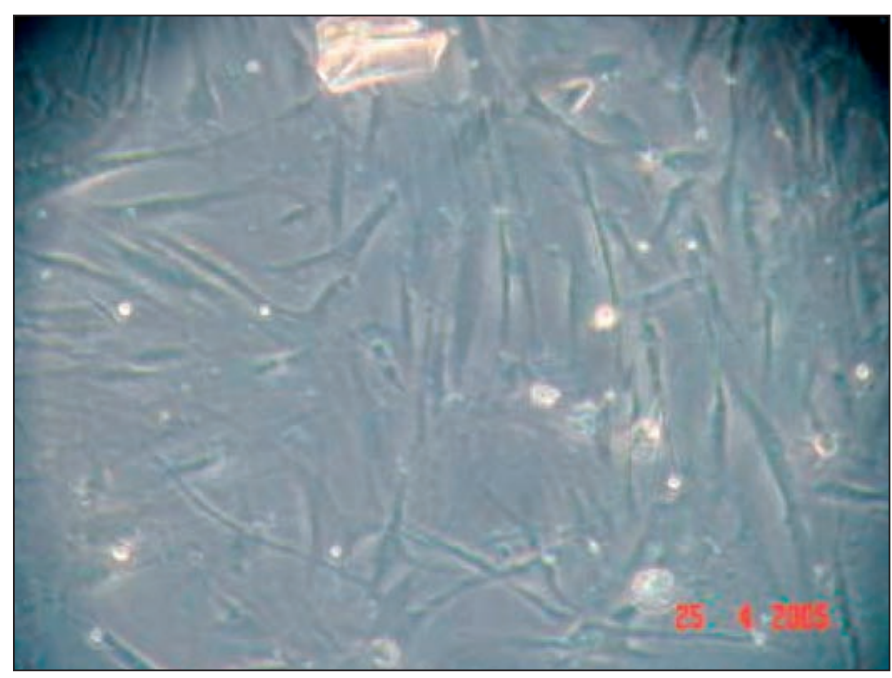

Figura 1 - Fibroblastos em crescimento nos frascos de Multiwell 
Imediatamente antes da exposição, o pH da solução era de 7.66, ou seja, a solução era discretamente alcalina.

Após a exposição das células ao tacrolimus, foram feitas as contagens em quatro momentos: 1) a primeira contagem foi realizada 1 dia após exposição; 2) a segunda contagem foi realizada 5 dias após exposição; 3) a terceira contagem foi realizada 12 dias após exposição; 4) a quarta contagem foi realizada 19 dias após exposição.

Em cada momento, foram contados os fibroblastos dos 4 compartimentos, sempre 3 de expostos e 1 de controle.

O método para contagem de fibroblastos foi através de hemocitômetro (câmara de Neubauer).

Primeiramente tripsinou-se as células, de modo a obter uma suspensão homogênea de fibroblastos, sem grumos. Com uma pipeta Pasteur de ponta fina, homogeneizou-se a suspensão pipetando-se algumas vezes para cima e para baixo. Retirou-se $50 \mu \mathrm{l}$ da suspensão e diluiu-se com $50 \mu \mathrm{l}$ de azul de Tripan, pois o corante marca os fibroblastos inviáveis, para que estes não fossem contados.

Retirou-se uma amostra com pipeta e aplicou-se nos locais indicados na câmara de Neubauer, de forma que o líquido escorreu por capilaridade entre a lâmina e a lamínula. Esperouse alguns segundos, focalizou-se e contou-se todas as células do quadrado delimitado grande central (16 quadrados menores), com aumento de 100 vezes.

Como o número de fibroblastos em cada quadrado grande era menor de 100, contou-se 5 quadrados. A concentração foi dada por:

$\frac{\mathrm{n}^{\circ} \text { de células contadas } \mathrm{x} 100^{2} \times 2}{\mathrm{n}^{\circ} \text { de quadrados grandes contados }}=\mathrm{n}^{\circ}$ de fibroblastos $/ \mathrm{ml}$

Os dados obtidos foram analisados estatisticamente, utilizando a técnica de Análise de variância para o modelo de medidas repetidas para grupos independentes, segundo o esquema fatorial $2 \times 2$.

\section{RESULTADOS}

Apesar de ter sido colhido material de 14 indivíduos, o subcultivo celular foi possível no material proveniente de 8 fibroblastos de cápsula de Tenon de pterígios e 6 de cápsulas de Tenon normais, devido a serem estas as amostras que apresentaram número de fibroblastos suficientes para realizar a exposição em triplicata, controle e contagem, nos quatro diferentes momentos experimentais estabelecidos.

As culturas de fibroblastos de Tenon normal, expostas ou não expostas à droga, apresentaram crescimento celular semelhante em todos os momentos de observação (Gráfico 1).

Avaliando-se os fibroblastos provenientes de cápsula de Tenon de pterígios, houve menor proliferação dos fibroblastos expostos, comparados aos não expostos, quando a avaliação foi feita um dia após a exposição $(\mathrm{p}<0,05)$. Depois disso, as culturas expostas retomaram seu crescimento, com taxa de replicação menor do que o grupo não exposto, sem diferença estatística nas avaliações de 5 e 12 dias. No último dia de avaliação (19 dias), as culturas expostas ultrapassaram o crescimento celular observado nas não expostas $(\mathrm{p}<0,05)$ (Gráfico 1).

Comparando-se o crescimento de fibroblastos de pterígios, assim como de cápsula de Tenon normal, observou-se que, tanto nas culturas de fibroblastos de pterígios, quanto nas de Tenon normal, com ou sem exposição à droga, a quantidade de células que proliferaram foi menor no primeiro dia de observação, com diferença significativa em relação aos demais momentos experimentais (Tabela 1).

\section{DISCUSSÃO}

A técnica de cultivo celular permite que se estude o efeito da droga em questão, o tacrolimus, sem a interferência de fatores exógenos, ou seja, a tendência das células de interesse, sem que fatores ambientais possam impedir que se conhe-

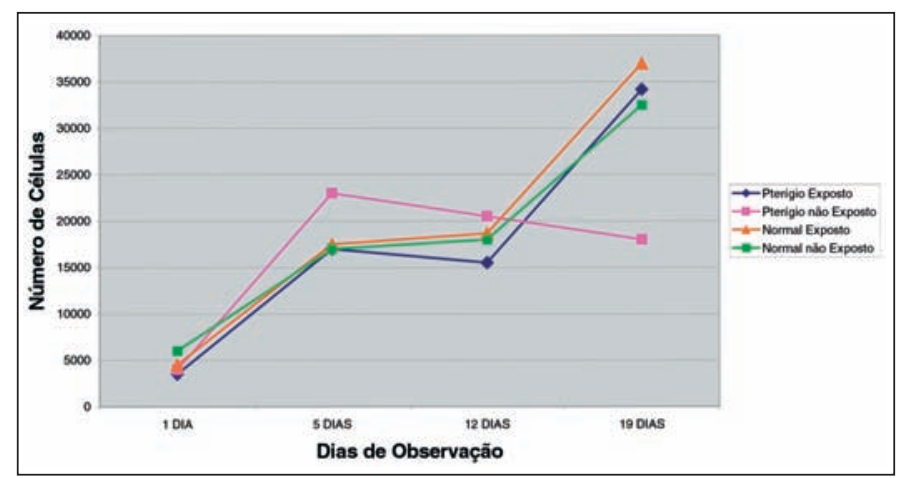

Gráfico 1 - Resposta dos fibroblastos da cápsula de Tenon normal e de pterígios à exposição ao tacrolimus

\begin{tabular}{|c|c|c|c|c|c|}
\hline \multirow{4}{*}{$\begin{array}{l}\text { Grupo } \\
\text { Pterígio }\end{array}$} & \multirow{4}{*}{$\begin{array}{c}\text { Exposição } \\
\text { Sim } \\
\text { Não }\end{array}$} & \multicolumn{4}{|c|}{ Momento de avaliação } \\
\hline & & 1 dia & 5 dias & 12 dias & 19 dias \\
\hline & & $3500 \pm 2167 a A \alpha$ & $17000 \pm 2500 a A \beta$ & $15500 \pm 15834$ aA $\beta$ & $34167 \pm 18500 \quad b A \beta$ \\
\hline & & $4000 \pm 16667 b A \alpha$ & $23000 \pm 16500$ aA $\beta$ & $20500 \pm 34500$ aA $\beta$ & $18000 \pm 20250$ aA $\beta$ \\
\hline \multirow[t]{2}{*}{ Normal } & Sim & $4517 \pm 2667 \mathrm{aA} \alpha$ & $17500 \pm 8000 a A \beta$ & $18667 \pm 14000$ aA $\beta$ & $37000 \pm 11000$ aA $\beta$ \\
\hline & Não & $6000 \pm 21334 \mathrm{aA} \alpha$ & $17000 \pm 14500 a A \beta$ & $18000 \pm 29334 a A \beta$ & $32500 \pm 40000$ aA $\beta$ \\
\hline
\end{tabular}


ça o real efeito de uma medicação que pode ser interessante no tratamento desta afecção que é tão comum em nosso meio.

Porém, o detalhamento da técnica de cultivo precisa ser rigorosamente seguido para que se consiga ter sucesso na proliferação celular, sendo necessário o fornecimento dos meios de cultivo em quantidade e freqüência corretas. Mesmo assim, no presente estudo, a proliferação com crescimento celular para que os espécimes fossem replicados em, no mínimo, três vezes, não foi possível em $100 \%$ das amostras.

No presente estudo foram utilizados apenas fibroblastos provenientes de portadores de pterígios recidivados, embora estudo anterior tenha mostrado não haver diferença significativa entre a migração e confluência entre pterígios primários ou recidivados ${ }^{(3)}$.

Entretanto, a quantidade de espécimes foi maior que o que se observa em outros estudos ${ }^{(4-6)}$, provavelmente por causa dos altos custos para a realização das culturas celulares e também por causa da dificuldade que as células fibroblásticas provenientes da conjuntiva possuem em se replicar.

A redução na proliferação celular sob efeito do tacrolimus ocorreu na observação feita 1 dia após a exposição. Depois disso, houve retomada da proliferação celular. Este comportamento pode estar relacionado a dois fatores: o tempo de ação da droga e a concentração utilizada. Vale lembrar que o tempo de ação desta droga, quando administrada via oral no pósoperatório de transplante renal, é de 12 horas. Não existem estudos a respeito do uso tópico na superfície ocular. Sendo assim, como houve redução da proliferação celular no primeiro dia após a exposição, esta deve ser uma droga que necessita de exposições mais freqüentes para que seja mantido o efeito antiproliferativo que foi inicialmente observado.

Estudos em cultura de fibroblastos serão muito importantes para que se conheça, além do efeito da droga sobre a replicação celular, a freqüência com que a droga deve ser usada.

Outro ponto a ser estabelecido seria a concentração ideal da droga para uso tópico. A dose aqui utilizada (1 molar) foi escolhida tendo por base um estudo realizado com cultura de explantes de tecido retiniano de fetos de ratos, onde avaliou-se a taxa de crescimento dos explantes após sua exposição ao tacrolimus $^{(7)}$. Desta forma, concentrações superiores a esta precisam ser testadas para que se conheça a dose inibitória mínima necessária para inibição do crescimento dos fibroblastos conjuntivais, os responsáveis pelo crescimento da lesão conjuntival.

Interessante notar que, tanto as células do pterígio, como as normais, tiveram a mesma resposta à droga.

E por último, a observação de que as células se replicam mais rapidamente no início do experimento, pode ser um indício de que entre o primeiro e o quinto dia após a exérese da lesão, o potencial para crescimento seja maior. Este fato tem confirmação clínica, quando muitas vezes, já no primeiro retorno do paciente, pode-se ver a tendência a recidiva da lesão conjuntival.

\section{CONCLUSÃO}

Os fibroblastos provenientes da cápsula de Tenon de pterígios recidivados apresentaram taxa de proliferação significativamente menor no primeiro dia após a exposição ao tacrolimus. Novos estudos devem ser realizados no sentido de se definir dose e tempo de exposição dos fibroblastos à droga, com o intuito de definir se o tacrolimus pode ser útil como tratamento coadjuvante do pterígio.

\section{ABSTRACT}

Purpose: To evaluate fibroblast proliferation activity of normal Tenon's capsule and of recurrent pterygia exposed in vitro to tacrolimus (FK506). Methods: A randomized prospective study was performed with 8 samples of recurrent pterygia and 6 samples of normal Tenon's capsule from the same patient with pterygium at the Faculdade de Medicina de Botucatu - UNESP. The samples were cultivated and exposed once to $1 \mathrm{M}$ tacrolimus (FK 506) and the proliferation rate was evaluated 1, 5, 12 and 19 days after the exposure. The data were statistically analyzed. Results: The fibroblasts from pterygia exposed in vitro to tacrolimus had a significantly lower proliferation rate than controls after one day of exposure $(\mathrm{p}<0.05)$. Nineteen days after exposure to tacrolimus, exposed cells proliferated more than the non-exposed. Conclusion: Tacrolimus is effective to inhibit proliferation of Tenon's capsule fibroblasts from pterygia one day after exposure. Further studies are needed to define the role of tacrolimus in pterygium treatment.

Keywords: Pterygium/pathology; Fibroblasts/pathology; Cell culture techniques; Cell proliferation; Recurrence; Tacrolimus/therapeutic use

\section{REFER̂̂NCIAS}

1. Perry HD, Donnenfeld ED. Topical $0,05 \%$ cyclosporin in the treatment of dry eye. Expert Opin Pharmacother. 2004;5(10):2099-107.

2. Bhargava A, Jackson WB, El-Defrawy SR. Ocular allergic disease. Drugs Today (Barc). 1998;34(11):957-71.

3. Viveiros MMH, Schellini SA, Rogato S, Rainho C, Padovani CR. Análise do cultivo de fibroblastos de pterígios primários e recidivados e da cápsula de Tenon normal. Arq Bras Oftalmol. 2006;69(1):57-62.

4. Baldó D BM, Arvelo F, Acevedo M. Estudio biomorfológico en cultivo de fibroblastos obtenidos de pterigión primário y pterigión recidivante tratados con Mitomicina C. Rev Oftalmol Venez. 1998;54(3):28-42.

5. Khaw PT, Ward S, Porter A, Grierson I, Hitchings RA, Rice NS. The longterm effects of 5-fluorouracil and sodium butyrate on human Tenon's fibroblasts. Invest Ophthalmol Vis Sci. 1992;33(6):2043-52.

6. Yamamoto T, Varani J, Soong HK, Lichter PR. Effects of 5-fluorouracil and mitomycin $\mathrm{C}$ on cultured rabbit subconjunctival fibroblasts. Ophthalmology. 1990;97(9):1204-10.

7. Shi YY, Young MJ. Effect of FK-506 on neurite outgrowth in retinal explants [abstract]. Invest Ophthalmol Vis Sci. 1999;40:3861. 